flagging films they consider to show an abnormality is useful in reducing the errors of interpretation (reported to be as high as $39 \%^{\mathrm{B}}$ ) made by casualty officers. We set up this study to assess the ability of radiographers to triage casualty radiographs, possibly with a view to their taking over the immediate reporting role from radiologists. It also provided an audit of the flagging system already in operation.

Compared with previous studies, the radiographers' overall error rate of $9 \cdot 4 \%$ is slightly worse than that of casualty officers. ${ }^{+6}$ If the percentage of abnormalities missed (14\%) is calculated, however, then the radiographers did considerably better than the casualty officers studied by Vincent $e t$ al. ${ }^{8}$ The main areas of disagreement were similar in both studies, although we were surprised by the lack of errors in radiographs of the spine in our study.

Every attempt was made to ensure that no extra effort was made by the radiographers during the study: they did not know when the study started and stopped, there was no education or feedback, and all films passing through the department (including those from outpatients and intensive care) were assessed but not all were included in the study. We also assumed that the radiologists' report was the gold standard. This may not be strictly true, particularly when some of the reporting is done by junior radiologists. ${ }^{+}$Our rapid reporting system includes some junior radiologists, and is the best we can offer the accident and emergency department with current staffing levels.

We deliberately did not assess radiographers' performance according to their grade, although a previous study suggested that the radiographers' accuracy correlated reasonably well with seniority.'

It has previously been suggested that radiographers should be able to take a greater role in interpreting radiographs, which would free radiologists from continual attendance in the accident and emergency department. ${ }^{910}$ This would increase job satisfaction for radiographers, who Swinburne considered were functioning below their full potential. ${ }^{10}$ This is already happening in other areas of imaging-for example, obstetric ultrasonography. Pressure to extend this area may increase when radiography becomes a degree qualification, as seems imminent.

Currently, the medical defence organisations accept a white sticker or red dot flagging system provided that all staff are aware that it is informal." The
Royal College of Radiologists stated that radiographers should confine themselves to measurements, not clinical opinions, ${ }^{12}$ and our evidence supports this view. Radiographers seem to be able to pick up more abnormalities than do casualty officers. Their overall error rate is, however, increased by a false positive rate of $7 \%$. This is not acceptable in a busy accident and emergency department.

Could the radiographers' performance be improved to a level at which they could take over the reporting of casualty films from radiologists? Swinburne suggested training a small number of radiographers in pattern recognition that would help them to distinguish normal from abnormal films. ${ }^{10}$ This method has not yet been tried or tested.

Our results show that triage of $x$ ray films by radiographers can be of use to casualty officers. Radiographers' overall error rate is, however, too high to allow them to take over completely from radiologists. We conclude that there should be no change in the current advice that all $x$ ray films in the casualty department should be reviewed by a radiologist, preferably immediately.

We thank all the radiographers and radiologists at $S t$ James's Hospital who took part in this study and Susan Baxter and Wendy Pepper, who typed the manuscript.

1 Berman L, de Lacey G, Twomey E, Twomey B, Welch T, Eban R. Reducing crrors in the accident and emergency department: a simple method using radiographers. BMF 1985;290:421-2

2 (ileadhill DNS, Thompson JY, Simms P. Can more efficient use be made of $\mathrm{x}$ ray examinations in the accident and emergency department? BMJ 1987 294:943-7.

3 Clarke JA, Adams JE. The application of clinical guidelines for skull radiography in the accident and emergency department: theory and practice. Clin Radiol 1990:41:152-5.

4 De Lacey GJ, Barker A, Harper J, Wignall B. An assessment of the clinical efforts of reporting accident and emergency radiographs. Br $\mathcal{F}$ Radiol 1980;53:304-9.

5 Mucci $B$. The selective reporting of $x$-ray films from the accident and emergency department. Injury 1983;14:343-4.

6 Wardrope J, Chennels PM. Should all casualty radiographs be reviews? BMY 1985;290:1639-40.

7 Fielding JA. Improving accident and emergency radiology. Clin Radiol 1990;41:149-51

8 Vincent CA, Driscoll PA, Audley RJ, Grant DS. Accuracy of detection of radiographic abnormalities by junior doctors. Arch Emergency Med 1988;5 $101-9$

9 Aberdour KR. Must radiologists do all the reporting? Br f Radiol 1976;49:573 10 Swinburne K. Pattern recognition for radiographers. Lancet 1971;i:589-90.

11 Medical Defence Union. Annual report 1988. London: MDU, 1988:21.

12 Craig TOMC. Registrar's report. Royal College of Radiologists Newsletter 1983;15:8-10.

(Accepted 19 1)ecember 1990)

\title{
Single umbilical artery and maternal smoking
}

\section{G Monica C Lilja}

Department of

Embryology, University of

Lund, S-223 62 Lund,

Sweden

G Monica C Lilja, MD, graduate student

BMF 1991;302:569-70
A single umbilical artery, occurring at a rate of about $0.5 \%$, is one of the most common congenital malformations in infants. It is significantly associated with low birth weight $(<2500 \mathrm{~g})$ and preterm birth $(<37$ weeks) and is more common in girls than boys.' It is also significantly associated with increased perinatal mortality and severe congenital malformations (unpublished data). I reviewed registry data on all infants born in Sweden between 1983 and 1986 to assess the association between having a single umbilical artery and maternal smoking.

\section{Subjects, methods, and results}

In Sweden nearly all infants (stillbirths after 28 weeks' gestation and live births) born during 1983-6 are registered in the medical birth registry. ${ }^{2}$ Maternal smoking is recorded at the first visit to a maternity health centre, usually at a gestational age of 10-12 weeks. The mothers were divided into three groups: non-smokers and smokers of less than 10 and 10 or more cigarettes a day. Information about maternal smoking was lacking in $6.7 \%$ of births.

The number of umbilical vessels was recorded by the attending midwife after gross inspection of the freshly cut umbilical cord. During 1983-6, 372066 births ( $97 \%$ of the total) were registered with information on the number of umbilical vessels. The analysis was restricted to the 1694 singleton infants who had a single umbilical artery and no known chromosome anomalies because a single umbilical artery is much more common in infants with chromosomal anomalies and in twins.'

The effect of maternal smoking on the risk of having an infant with a single umbilical artery was estimated as an odds ratio by the Mantel-Haenszel procedure ${ }^{4}$ after stratification for maternal age and parity. Approximate $95 \%$ confidence intervals were calculated with Miettinen's technique.

The table shows the smoking habits of women 
according to the number of umbilical vessels in the infant. In all, 1580 women with an infant who had a single umbilical artery gave information about smoking.

Numbers (percentages) of infants with single umbilical artery and with three vessels by maternal smoking habit (twins and infants with chromosomal anomalies are excluded)

\begin{tabular}{|c|c|c|c|c|}
\hline \multirow[b]{2}{*}{ Umbilical vessels } & \multicolumn{3}{|c|}{ Maternal smoking (cigarettes/day) } & \multirow[b]{2}{*}{ Total } \\
\hline & 0 & $<10$ & $>10$ & \\
\hline $\begin{array}{l}\text { Single umbilical } \\
\text { artery }\end{array}$ & $973(61 \cdot 6$ & ) $370(23 \cdot 4)$ & $237(15 \cdot 0)$ & 1580 \\
\hline Three vessels & $235976(69 \cdot 7$ & $62525(18 \cdot 5)$ & $39851(11 \cdot 8)$ & 338352 \\
\hline Crude odds ratio ${ }^{\star}$ & & 1.44 & 1.44 & \\
\hline
\end{tabular}

^Unadjusted for maternal age and parity.

To study whether the increased number of infants with a single umbilical artery among women who smoked was due to an abnormal distribution of maternal age and parity, ${ }^{1}$ an odds ratio was calculated for single umbilical artery in infants of such women after stratification for maternal age and parity. The odds ratio was 1.46 with a $95 \%$ confidence interval of 1.31 to 1.61 , and no difference was found between the two groups of smokers.

Birth weight was low $(<2500 \mathrm{~g})$ in 191 out of 1674 infants with a single umbilical artery for whom the weight was known.' After stratification for age and parity, the expected number was 62.1 and after stratification for smoking as well $71 \cdot 4$. A birth weight below $1500 \mathrm{~g}$ was found in 45 infants in this study. The expected number was 9.9 after stratification for age and parity and 11.6 after stratification for smoking as well. This means that maternal smoking contributes only to a minor extent to the low birth weight of infants with a single umbilical artery.

\section{Comment}

Published reports show a close association between tobacco smoking and the development of arterial diseases. Asmussen and Kjeldsen found pronounced degenerative changes in the endothelium of umbilical arteries in newborn infants of women who smoked. I found a significant association between smoking in women and the occurrence of single umbilical artery in their infants. As far as I know it has not been reported before; the only published study I could find that associated smoking with a single umbilical artery had an inadequate control group. ${ }^{3}$

1 Lilia $M$. Infants with single umbilical artery studied in a national registry. I. General epidemiological characteristics. Paediatric and Perinatal Epidemiology 1991;1:27-36.

2 Cnattingius S, Ericson A, Gunnarskog J, Källen B. A quality study of a Medical Birth Registry. Scand J Soc Med 1990;18:143-8.

Bryan EM, Kohler HG. The missing umbilical artery. I. Prospective study based on a maternity unit. Arch Dis Child 1974;49:844-52.

4 Mantel N, Haenszel W. Statistical aspect of the analysis of data from

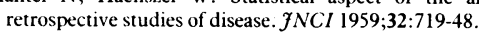

5 Asmussen I, Kjeldsen K. Intimal ultrastructure of human umbilical artery. Observations on arteries from newborn children of smoking and nonsmoking mothers. Circ Res i 975 ;36:579-89.

(Accepted 21 November 1990

\section{An implantable device for long term venous access in chronic lung conditions}

\section{J Davies, R G Wilson, $M$ Keston, S J Nixon}

Western General Hospital, Edinburgh EH4 2XU

M J Davies, FRCS, registrar

R G Wilson, FRCS, registrar

$M$ Keston, $\mathrm{MB}$, cystic fibrosis fellow

S J Nixon, FRCS, consultant

Correspondence to:

Mr Nixon, D Block Surgical Unit.

BMF 1991;302:570-1

Patients with chronic lung diseases often require intravenous antibiotics over long periods. Thromboses may occur in peripheral veins. Tunnelled, external catheters facilitate venous access but need regular dressing, have a high rate of septic complications, and have detrimental effects on the patient's lifestyle.' We therefore examined a totally implantable, plastic device (Intraport, Fresenius).

\section{Patients, methods, and results}

The Intraport device comprises a lightweight plastic infusion chamber ( $35 \mathrm{~mm}$ diameter $\times 14.8 \mathrm{~mm}$ high) with a self sealing silicone membrane attached to a $2.5 \mathrm{~mm}$ diameter silicone catheter (figure). The membrane withstands at least 2000 punctures with an atraumatic needle (Huber). The port is inserted under local anaesthesia through a single incision over the deltopectoral groove. The cephalic vein is identified. A subcutaneous pocket is created in the anterior chest wall at a site previously chosen by the patient. The device is flushed with heparinised saline. The catheter is cut to length and advanced until its tip lies in the superior vena cava. The reservoir is positioned in the pocket and the skin incision sutured.

We have inserted 13 of these catheters in 12 patients aged 16 to 64 (five men, seven women). Ten patients had cystic fibrosis, one aspergillosis, and one chronic bronchiectasis. No perioperative or early complications developed. One patient died four months after insertion from progression of respiratory disease. One port occluded, owing to the inexperience of the staff,

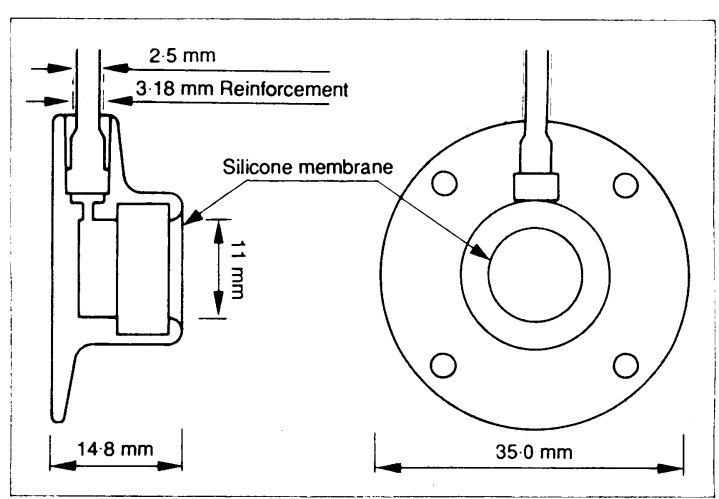

Dimensions of plastic implantable port providing long term venous access

while the patient was in hospital; the blockage was successfully treated by dissolution. Another catheter failed, and radiography showed coiling in the subcutaneous pocket, the tip lying outside the vein; the device was replaced. Eleven catheters were functioning well between 12 and 30 months after insertion, the median duration being 18 months. No episodes of sepsis at the site of the catheter occurred.

\section{Comment}

The demand for long term venous access is rising and indications are widening. Subcutaneous implantable systems have been used to give chemotherapy for cancer and in patients requiring parenteral nutrition. Patients are often immunocompromised, and sepsis at the site of the catheter remains a problem and leads to premature removal of the catheter. The demand for implantable ports has come particularly from patients. Cosmetically such parts are far superior to external systems as dressings are unnecessary. The catheter is less prone to damage and cannot be accidentally removed. The one failure of a catheter among our 